\title{
Effectiveness of ICD therapy in real clinical practice. The Olomouc ICD Registry
}

\author{
Milos Taborskya, Tomas Skalaa, Marian Fedorco ${ }^{a}$, Vlastimil Doupal ${ }^{\mathrm{a}}$, Ingrid Sovova ${ }^{\mathrm{a}}$, Jiri Jarkovsky ${ }^{\mathrm{b}, \mathrm{c}}$, Klara Benesova ${ }^{\mathrm{b}, \mathrm{c}}$, \\ Monika Bezdekova ${ }^{\mathrm{b}}$, Marek Vichaa ${ }^{\mathrm{a}}$ Josef Danek ${ }^{\mathrm{d}}$, Josef Kautzner ${ }^{\mathrm{e}}$
}

\begin{abstract}
Background. Clinical parameters linked to a low benefit of ICD implantation and increased mortality risks are needed for an individualized assessment of potential benefits and risks of ICD implantation.

Methods. Analysis of a prospective registry of all patients hospitalized from 2009 to 2019 in a single centre for a first implantation of any type of ICD.

Results. A total of 2,681 patients were included in the registry. Until the end of follow-up (38.4 \pm 29.1 months), 682 (25.4\%) patients died. The one-year mortality in all patients, the one-year CV mortality, the three-year mortality in all patients, and the three-year CV mortality were $7.8 \%, 5.7 \%, 20.6 \%$, and $14.8 \%$, respectively. There was a statistically significant difference when the subgroups were compared according to the type of cardiomyopathy. No significant difference was found between primary and secondary prevention and between the types of devices. Male gender, age $\geq 75$ years, diabetes mellitus, and atrial fibrillation were associated with a significantly increased mortality risk.

Conclusion. In an analysis of a long-term follow-up of 2,681 ICD patients, we found no mortality difference between patients with ischemic or non-ischemic cardiomyopathy and in the device type. A higher mortality risk was found in men, patients older than 75 years, diabetics, and those with atrial fibrillation.
\end{abstract}

Key words: implantable cardioverter-defibrillator, heart failure, primary prevention, time to shock, sppropriate shock, mortality

Received: September 23, 2021; Revised: December 7, 2021; Accepted: December 8, 2021; Available online: December 17, 2021 https://doi.org/10.5507/bp.2021.071

(c) 2021 The Authors; https://creativecommons.org/licenses/by/4.0/

${ }^{a}$ Department of Internal Medicine I - Cardiology, University Hospital Olomouc, I. P. Pavlova 6, 775 20 Olomouc, Czech Republic 'Institute of Health Information and Statistics of the Czech Republic, Palackeho nam. 4, P.O. BOX 60, 12801 Praha 2, Czech Republic Institute of Biostatistics and Analyses at the Faculty of Medicine of the Masaryk University (IBA FM MU) in Brno, Czech Republic ${ }^{d}$ Department of Cardiology, Central Military Hospital Prague, U Vojenske nemocnice 1200, 16902 Praha 6, Czech Republic eInstitute for Clinical and Experimental Medicine, Videnska 1958, 14021 Praha 4, Czech Republic Correspondence author:Tomas Skala, e-mail: tomasskala@gmail.com

\section{BACKGROUND}

Implantable cardioverter-defibrillator (ICD) implantation has a mortality benefit when compared with guideline-directed medical therapy according to several randomized controlled trials in patients with heart failure (HF) (ref. $\left.{ }^{1-3}\right)$. However, these trials were finished a long time ago, and the current treatment of HF has led to a decrease in sudden cardiac death (SCD) rates since the early 2000s (ref. ${ }^{4}$ ). Thanks to the modern treatment of ischemic heart disease, HF, and other comorbidities, the SCD risk profile of patients indicated for ICD implantation has changed dramatically when compared with the situation at the time of the realization of legacy ICD studies. An analysis of 12 trials conducted between 1995 and 2014 demonstrated a $44 \%$ decline in the SCD rate within those twenty years ${ }^{5}$. This decrease in the SCD rate resulted in a very low rate of appropriate life-saving shocks in primary prevention patients 6 . Thus, the majority of patients with an ICD implanted for primary prevention do not experience a life-saving shock. A recent analysis of SCD survivors showed that, before the event, only a minority of these patients had been eligible for primary prevention ICD implantation? ${ }^{7}$ ICD implantation is still not without risk as it may be associated with a significant increase in morbidity due to device infections, inappropriate shocks, as well as increased hospitalizations, healthcare costs, and reduced survival ${ }^{8}$. Left ventricular ejection fraction (LVEF) remains the main parameter for the selection of patients for primary prevention. However, not all patients with a low LVEF derive benefit from ICD implantation. Modern pharmacotherapy of HF with sacubitril-valsartan significantly decreases the occurrence of ventricular tachyarrhythmias 9 . A better selection of patients for primary prevention is required. A clear benefit can be demonstrated only in patients with a high risk of appropriate ICD intervention and low risk of non-arrhythmic mortality. Specific subgroups of patients, such as diabetics and those older than 75 years seem to derive a lower benefit from ICD implantation ${ }^{10}$. Clinical parameters linked to a low benefit of primary prevention ICD implantation and increased mortality risks are needed for an assessment of potential benefits and risks of this treatment. A personalized assessment of the individual risk of SCD, based not solely on LVEF, should be at the core of a modern approach to indication for ICD implantation. This would allow us to avoid the many unnecessary ICD implantations in patients with an ejection fraction below $35 \%$, and 
at the same time to protect those with an ejection fraction $>35 \%$ who carry a high individual risk from targeted CD implantation ${ }^{11}$.

\section{METHODS}

\section{Study population}

The Olomouc registry is a prospective registry of all patients hospitalized in a single centre (University Hospital Olomouc, Czech Republic) for a first implantation of any type of ICD with or without cardiac resynchronization therapy (CRT) for primary or secondary prevention indication according to currently available guidelines. This registry was initiated in 2008 and was approved by the local institutional review board. Patients started to be enrolled in the registry on 1 November 2009. These data were part of the national ICD registry. An independent statistical analysis of this part of the national ICD registry was done by the Institute of Biostatistics and Analyses at the Faculty of Medicine of the Masaryk University (IBA FM MU) in Brno. Only patients with at least 12 months of follow-up were chosen to be included in the statistical analysis, so the last patient included was implanted in December 2019. From January 2009 to December 2019, we enrolled 2,681 patients. Patients with reimplantation and device upgrade were not included, and nor were those with a subcutaneous ICD. Patients were enrolled in the registry during the index hospitalization at the time of initial device implantation. Data were collected prospectively and included demographic and clinical characteristics including age, gender, BMI, NYHA class, comorbidities and pharmacotherapy, type of cardiomyopathy, type of device and electrode, and echocardiographic and ECG parameters.

\section{Follow-up and study endpoints}

All patients were followed up in the implanting centres' outpatient department every 3-6 months. Cardiovascular (CV) and non-CV deaths were documented. Their distinction was based on a review of the death certificate issued by the attending physician. If a patient missed two appointments for outpatient visits, his or her general practitioner or local cardiologist was contacted to ascertain if the patient was still alive. In patients lost to follow-up, these physicians and the Institute of Health Information and Statistics of the Czech Republic were consulted to find out if the patient was still alive and to specify the cause of death (CV or non-CV).

\section{Study endpoints}

The primary endpoint was death from any cause. The secondary endpoint was $\mathrm{CV}$ and non-CV death.

\section{Statistical analysis}

The statistical analysis focused on the differences in subgroups with different gender, age, presence of atrial fibrillation (AF) and diabetes mellitus (DM), as well as on primary and secondary endpoints. These subgroups were further analysed according to the type of implan-
Table 1. Baseline demographics of the whole patient group.

\begin{tabular}{|c|c|}
\hline Patients (n=2 681) & \\
\hline Age & $66.3 \pm 11.7$ \\
\hline Age $\geq 75$ & $633(23.7 \%)$ \\
\hline \multicolumn{2}{|l|}{ Gender } \\
\hline Men & $2071(77.2 \%)$ \\
\hline Women & $610(22.8 \%)$ \\
\hline BMI & $28.7 \pm 5.2$ \\
\hline \multicolumn{2}{|l|}{ Device type } \\
\hline Single-chamber ICD & $1466(54.7 \%)$ \\
\hline Dual-chamber ICD & $144(5.4 \%)$ \\
\hline CRT & $1069(39.9 \%)$ \\
\hline \multicolumn{2}{|l|}{ Type of indication } \\
\hline Secondary prevention & $462(17.2 \%)$ \\
\hline Primary prevention & $2199(82.8 \%)$ \\
\hline \multicolumn{2}{|l|}{ Type of cardiomyopathy } \\
\hline Ischemic cardiomyopathy & $1494(55.7 \%)$ \\
\hline Non-ischemic cardiomyopathy & $1187(44.3 \%)$ \\
\hline \multicolumn{2}{|l|}{ Comorbidities } \\
\hline Diabetes mellitus & $1049(39.1 \%)$ \\
\hline Hepatopathy & $63(2.3 \%)$ \\
\hline COPD & $255(9.5 \%)$ \\
\hline Chronic kidney disease & $275(10.3 \%)$ \\
\hline Stroke & $156(5.8 \%)$ \\
\hline Cancer & $47(1.8 \%)$ \\
\hline \multicolumn{2}{|l|}{$\mathbf{A F}$} \\
\hline AF paroxysmal & $174(6.5 \%)$ \\
\hline AF persistent & $431(16.1 \%)$ \\
\hline \multicolumn{2}{|l|}{ Pharmacotherapy } \\
\hline Anticoagulation & $979(36.5 \%)$ \\
\hline Antiaggregation & $1164(43.4 \%)$ \\
\hline Digoxin & $93(3.5 \%)$ \\
\hline Class I antiarrhythmics & $30(1.1 \%)$ \\
\hline Class II antiarrhythmics & $1825(68.0 \%)$ \\
\hline Class III antiarrhythmics & $184(6.8 \%)$ \\
\hline Class IV antiarrhythmics & $55(2.1 \%)$ \\
\hline Vasodilatation therapy & $339(12.6 \%)$ \\
\hline Antihypertensives & $1022(38.1 \%)$ \\
\hline Diuretics & $2031(75.8 \%)$ \\
\hline ACE-inhibitors & $1107(41.3 \%)$ \\
\hline Sacubitril-Valsartan & $379(14,1 \%)$ \\
\hline $\mathrm{ARB}$ & $47(1.8 \%)$ \\
\hline Statins & $1109(41.4 \%)$ \\
\hline \multicolumn{2}{|l|}{ Left ventricular ejection fraction } \\
\hline $\mathrm{EF}>50 \%$ & $126(4.7 \%)$ \\
\hline EF $40-49 \%$ & $239(8.9 \%)$ \\
\hline EF $30-39 \%$ & $1285(47.9 \%)$ \\
\hline $\mathrm{EF}<30 \%$ & $938(35.0 \%)$ \\
\hline \multicolumn{2}{|l|}{ NYHA class } \\
\hline NYHA I & $163(6.1 \%)$ \\
\hline NYHA II & $1378(51.4 \%)$ \\
\hline NYHA III & $986(36.8 \%)$ \\
\hline NYHA IV & $31(1.2 \%)$ \\
\hline \multicolumn{2}{|l|}{ ECG } \\
\hline QRS (ms) & $115.5 \pm 36.2$ \\
\hline LBBB & $957(35.7 \%)$ \\
\hline
\end{tabular}

BMI=body mass index; $\mathrm{CRT}=$ cardiac resynchronization therapy; $\mathrm{COPD}=$ chronic obstructive pulmonary disease; $\mathrm{AF}=$ atrial fibrillation; $\mathrm{ARB}=$ angiotensin receptor blockers; NYHA=New York Heart Association class. 





tation, type of device, and type of cardiomyopathy. Standard descriptive statistics was used in the analysis; mean supplemented by standard deviation or median supplemented by interquartile range for continuous variables, and absolute and relative frequencies for categorical variables. Statistical significance of differences among patient groups was evaluated using the Pearson Chi-Square test for categorical variables and the Mann-Whitney or Kruskal-Wallis tests for continuous variables. Survival probability was calculated and visualized by the KaplanMeier method. Statistical significance of outcome differences in survival was assessed with the log-rank test. The analysis was computed using SPSS 25.0.0.1.

\section{RESULTS}

\section{Demographics}

A total of 2,681 patients were included in the registry. The follow-up period was $38.4 \pm 29.1$ months on average. A single-chamber ICD was implanted in 1,466 cases, dual-chamber ICD in 144 cases, and ICD with CRT (CRT-D) in 1,069 cases. Baseline demographics of the whole patient group can be seen in Table 1. Differences in subgroups according to the type of implantation, type of device, and type of cardiomyopathy are depicted in Table 2.

Categorial variables are evaluated using the Pearson's Chi-Squared test. Continuous variables are evaluated using the Mann-Whitney or Kruskal-Wallis tests. $\mathrm{BMI}=$ body mass index; $\mathrm{CRT}=$ cardiac resynchronization therapy; $\mathrm{AF}=$ atrial fibrillation; NYHA=New York Heart Association class.

\section{Mortality}

Mortality in the whole group and in subgroups according to the type of implantation, type of device, and type of cardiomyopathy is shown in Table 3 . Until the end of follow-up, of the 2,681 patients, 682 (25.4\%) died. There was a statistically significant difference when the subgroups were compared according to the type of cardiomyopathy. No significant difference was found between primary and secondary prevention and between the types of devices.

Basic demographic characteristics of patients with death from all causes according to indication for ICD implantation are shown in Fig. 1.

The survival probability according to the type of death (total, $\mathrm{CV}$, and non-CV) in the whole patient group is shown in Fig. 2.

The one-year mortality in all patients was $7.8 \%$; the one-year CV mortality $5.7 \%$; the three-year mortality in all patients $20.6 \%$; and the three-year CV mortality was $14.8 \%$. The survival probability (all-cause death) according to the type of implantation, type of device, and type of cardiomyopathy is shown in Fig. 2. There was a statistically significant difference in the survival probability when ischemic $(n=1,494)$ and non-ischemic $(n=830)$ cardiomyopathies were compared ( 421 /28.2\%/ vs. 198 /23.9\%/; $P<0.001)$. There was no statistically significant difference in the survival probability when the secondary $(n=462)$ and primary $(n=2,199)$ prevention indications for implantation ( $134 / 29.0 \% /$ vs. $535 / 24.3 \% / ; P=0.673)$ and single-chamber $(\mathrm{n}=1,466)$ vs. dual-chamber $(\mathrm{n}=144)$ vs. CRT $(n=1,069)$ were compared $(338 / 23.1 \% /$ vs. 36 /25.0\%/ vs. 308 /28.8\%/; $P=0.193$ ). Survival probability classified according to gender, age, AF, and DM is shown in Fig. 3.

\section{Mortality in subgroups \\ Gender}

Survival probability of women $(n=610)$ and men $(n=2,071)$ according to the type of implantation, type of device, type of cardiomyopathy is shown in Fig. 4. Women in general had lower mortality than men $(126 / 20.7 \%$ /



Fig. 1. Basic demographic characteristics of patients with death from all causes according to indication for ICD implantation. 

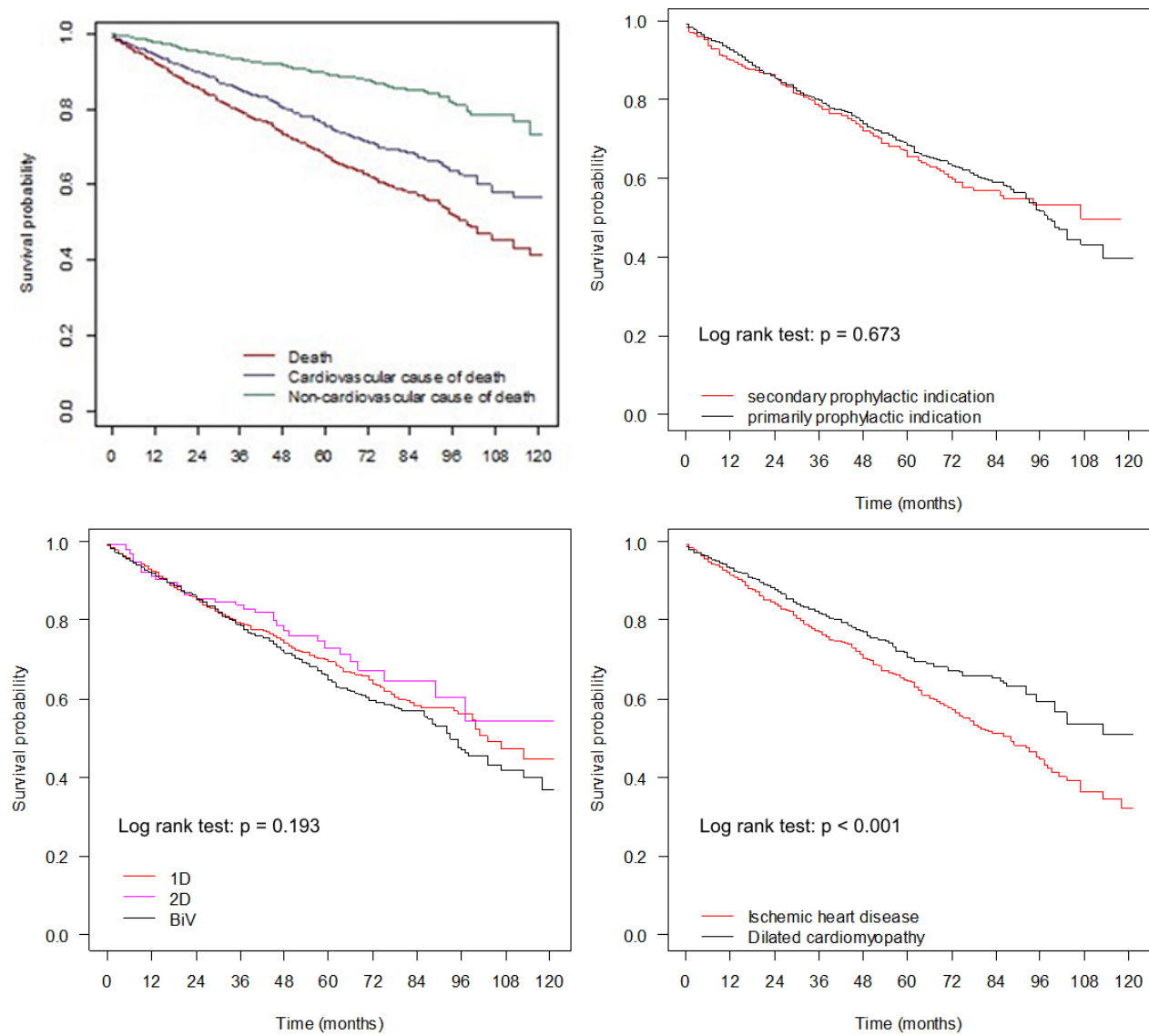

Fig. 2. Survival probability according to the type of implantation, type of device, type of cardiomyopathy, and type of death (total, cardiovascular, and non-cardiovascular).
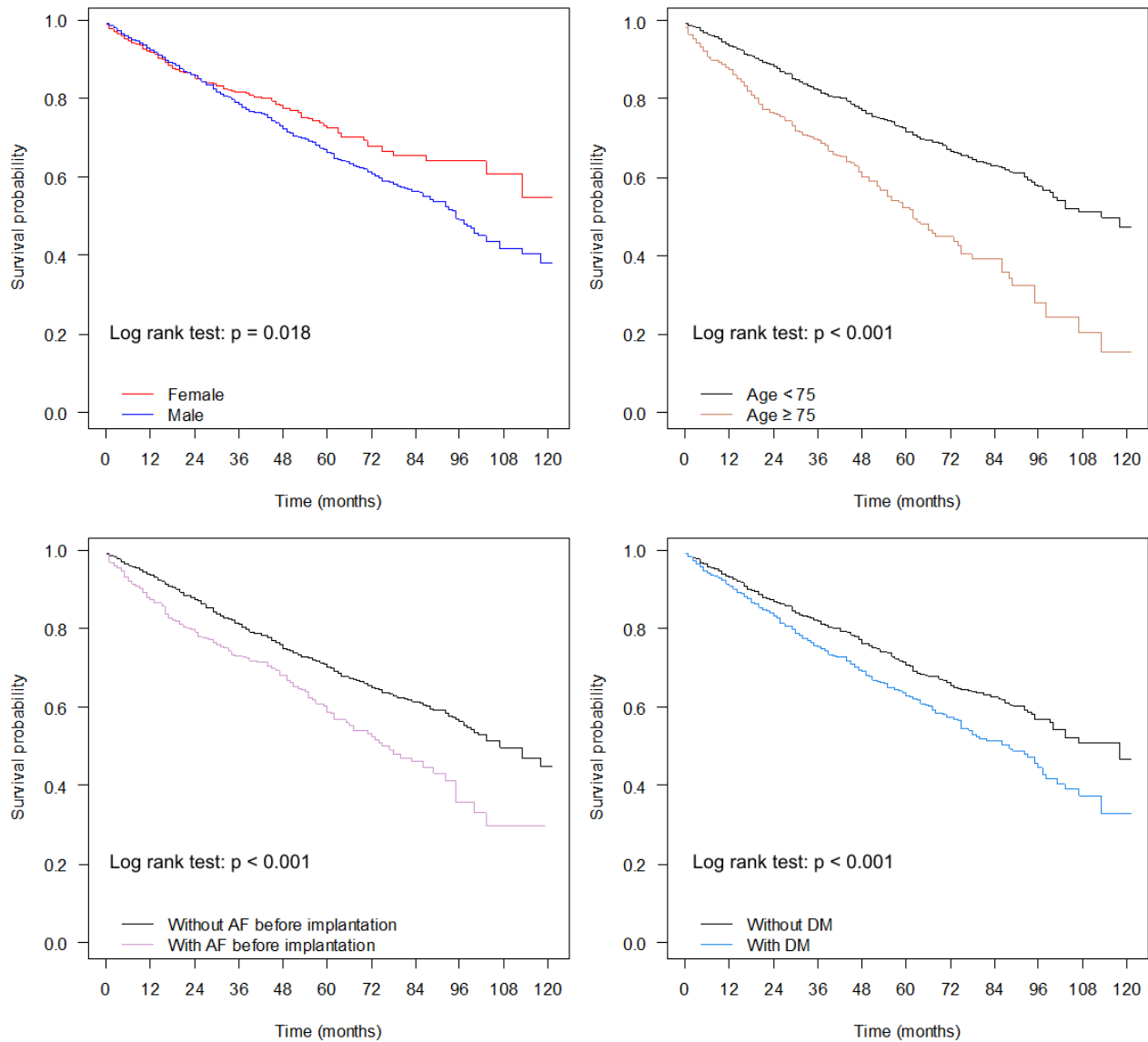

Fig. 3. Survival probability classified according to gender, age, atrial fibrillation, and diabetes mellitus. 

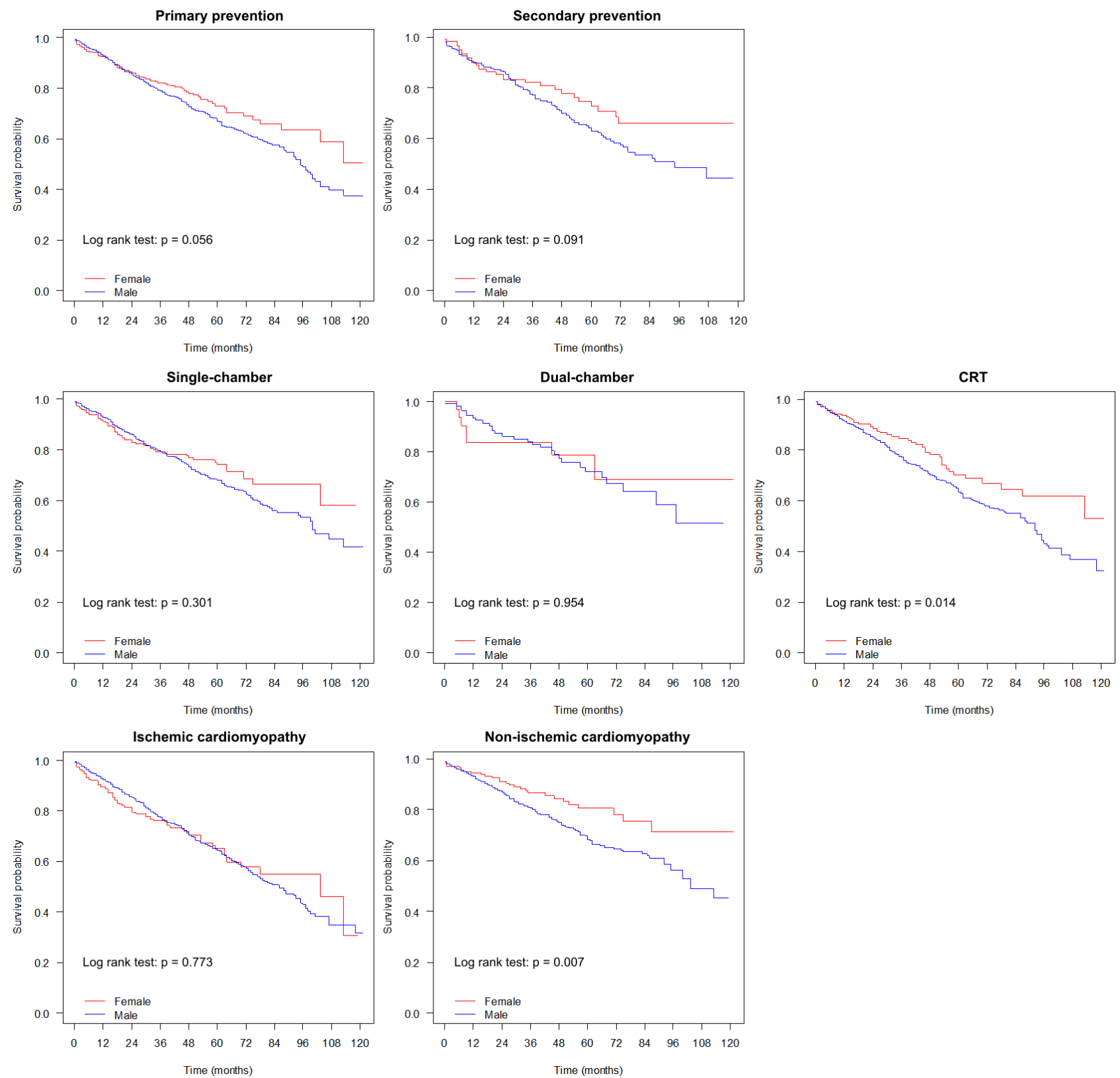

Fig. 4. Survival probability of women and men according to the type of implantation, type of device, and type of cardiomyopathy.

vs. $556 / 26.9 \% / ; P=0.018)$. This mortality difference was driven by a significantly better survival of women than men with non-ischemic cardiomyopathy $(29 / 15.5 \% /$ vs. $169 / 26.3 \% / ; P=0.007)$ and with CRT ( $47 / 21.4 \% /$ vs. 261 /30.7\%/; $P=0.014)$. No statistically significant difference was found in all types of implantation (94/19.6\%/ vs. 441 /25.7\%/; $P=0.056$ in primary prevention; $29 / 23.0 \% /$ vs. $105 / 31.3 \% / ; P=0.091$ in secondary prevention); in singlechamber ICDs ( $72 / 20.2 \% /$ vs. $266 / 24.0 \% / ; P=0.301)$; dual-chamber ICDs ( $7 / 20.6 \% /$ vs. $29 / 26.4 \% / ; P=0.954)$; and in ischemic cardiomyopathy ( $81 / 26.6 \% /$ vs. 340 /28.6\%/; $P=0.773$ ).

\section{Age}

Survival probability of all patients younger $(n=2,048)$ or older $(n=633)$ than 75 years according to the type of implantation, type of device, and type of cardiomyopathy is shown in Fig. 5. The difference in mortality was significant in general (467 /22.8\%/ vs. 215 /34.0\%/; $P<0.001)$; in all types of implantation (364 /21.8\%/ vs. $171 / 32.4 \%$; $P<0.001$ in primary prevention; $95 / 26.2 \% /$ vs. $39 / 39 \% /$; $P=0.001$ in secondary prevention); all types of devices ( 225 / 19.5\%/ vs. 113 /36.0\%/; $P<0.001$ in single-chamber; $25 / 21.4 \%$ / vs. $11 / 40.7 \% / ; P=0.029$ in dual-chamber; 217 /27.8\%/ vs. 91 /31.4\%/; $P<0.001$ in CRT) as well as in all types of cardiomyopathies ( $246 / 25.0 \%$ / vs. 137 /36.8\%/; $P<0.001$ in ischemic cardiomyopathy; $145 / 21.5 \% /$ vs. 53 /34.0\%/; $P<0.001$ in non-ischemic cardiomyopathy).

\section{Atrial fibrillation}

Survival probability of all patients with $(n=602)$ or without $(n=2,079)$ atrial fibrillation prior to implantation according to the type of implantation, type of device, and type of cardiomyopathy is shown in Fig. 6. The difference 

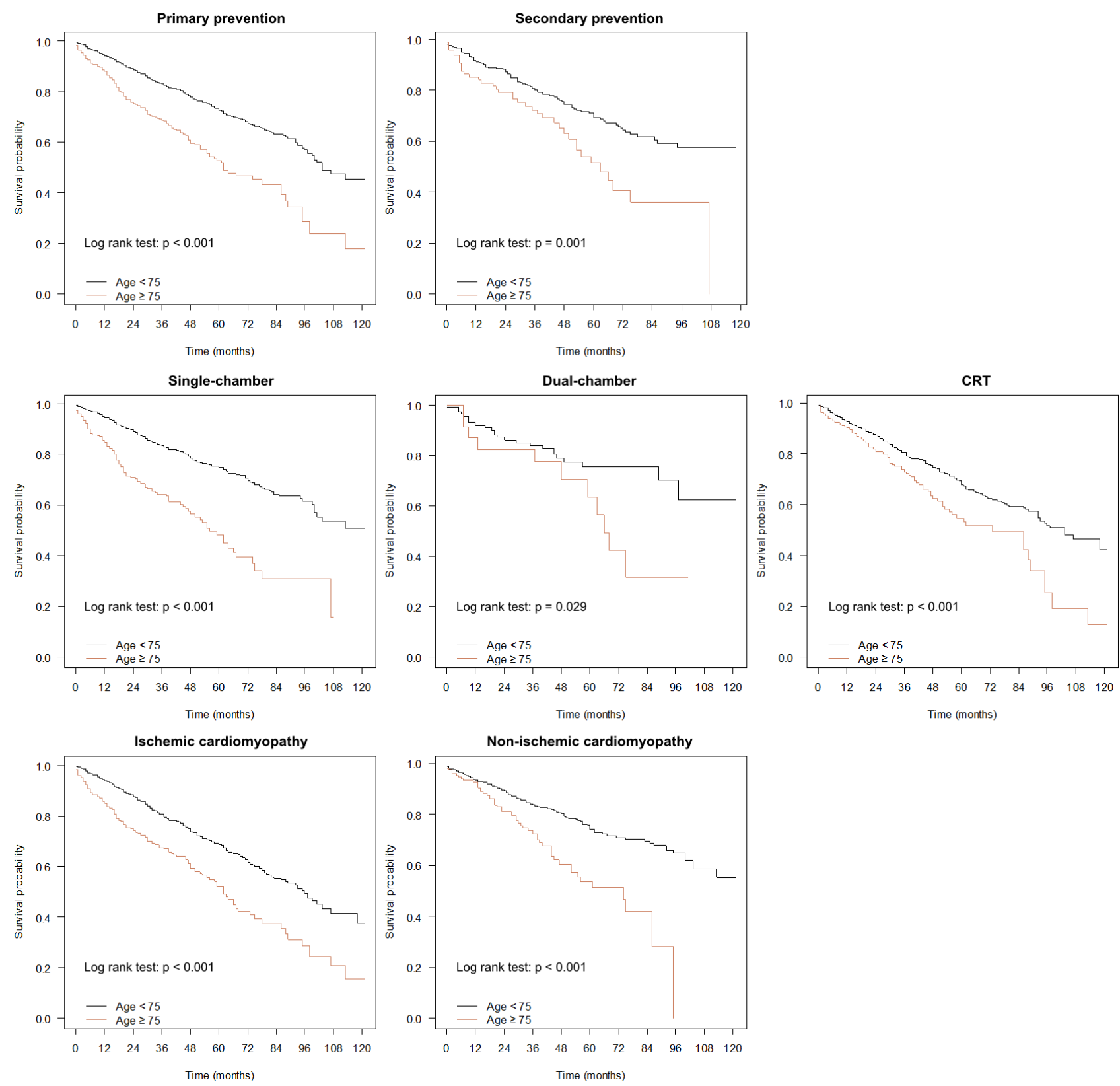

Fig. 5. Survival probability of all patients younger or older than 75 years according to the type of implantation, type of device, and type of cardiomyopathy.

in mortality was significant in general (194/32.3\%/ vs. 488 /23.5\%/; $P<0.001$ ); in all types of implantation (155 /30.4\%/ vs. $380 / 22.5 \% /$; $P<0.001$ in primary prevention; $33 / 38.4 \%$ / vs. $101 / 26.9 \% / ; P=0.002$ in secondary prevention); in single-chamber ICDs (105/35.4\%/ vs. 233 /19.9\%/; $P<0.001$ ); CRTs ( $83 / 30.5 \% /$ vs. 225 /28.2\%/; $P=0.042)$ as well as in all types of cardiomyopathy $(88$ /35.3\%/ vs. 295 /26.6\%/; $P<0.001$ in ischemic cardiomyopathy; 77 /32.3\%/ vs. 121 /20.4\%/; $P<0.001$ in non-ischemic cardiomyopathy). The difference was not significant in dual-chamber devices $(6 / 19.4 \% /$ vs. $30 / 26.5 \% / ; P=0.593)$.

\section{Diabetes mellitus}

Survival probability of all patients with $(n=1,049)$ or without $(n=1,632)$ diabetes mellitus prior to implanta- tion according to the type of implantation, type of device, and type of cardiomyopathy is shown in Fig. 7. The difference in mortality was significant in general (311/29.6\%/ vs. $371 / 22.7 \% / ; P<0.001)$; in all types of implantation ( $256 / 28.8 \% /$ vs. $279 / 21.3 \% / ; P<0.001$ in primary prevention; $48 / 32.2 \% /$ vs. $86 / 27.5 \% / ; P=0.110$ in secondary prevention); in single-chamber ICDs (159/30.0\%/ vs. 179 /19.9\%/; $P<0.001)$ as well as in all types of cardiomyopathies ( $188 / 30.0 \% /$ vs. $195 / 26.7 \% / ; P=0.029$ in ischemic cardiomyopathy; 86 /29.4\%/ vs. 112 /20.9\%/; $P=0.010$ in non-ischemic cardiomyopathy). The difference was not significant in dual-chamber devices ( $17 / 29.3 \% /$ vs. 19 /22.1\%/; $P=0.220$ ) and CRTs ( $135 / 32.1 \% /$ vs. $173 / 26.7 \% /$; $P=0.104)$. 

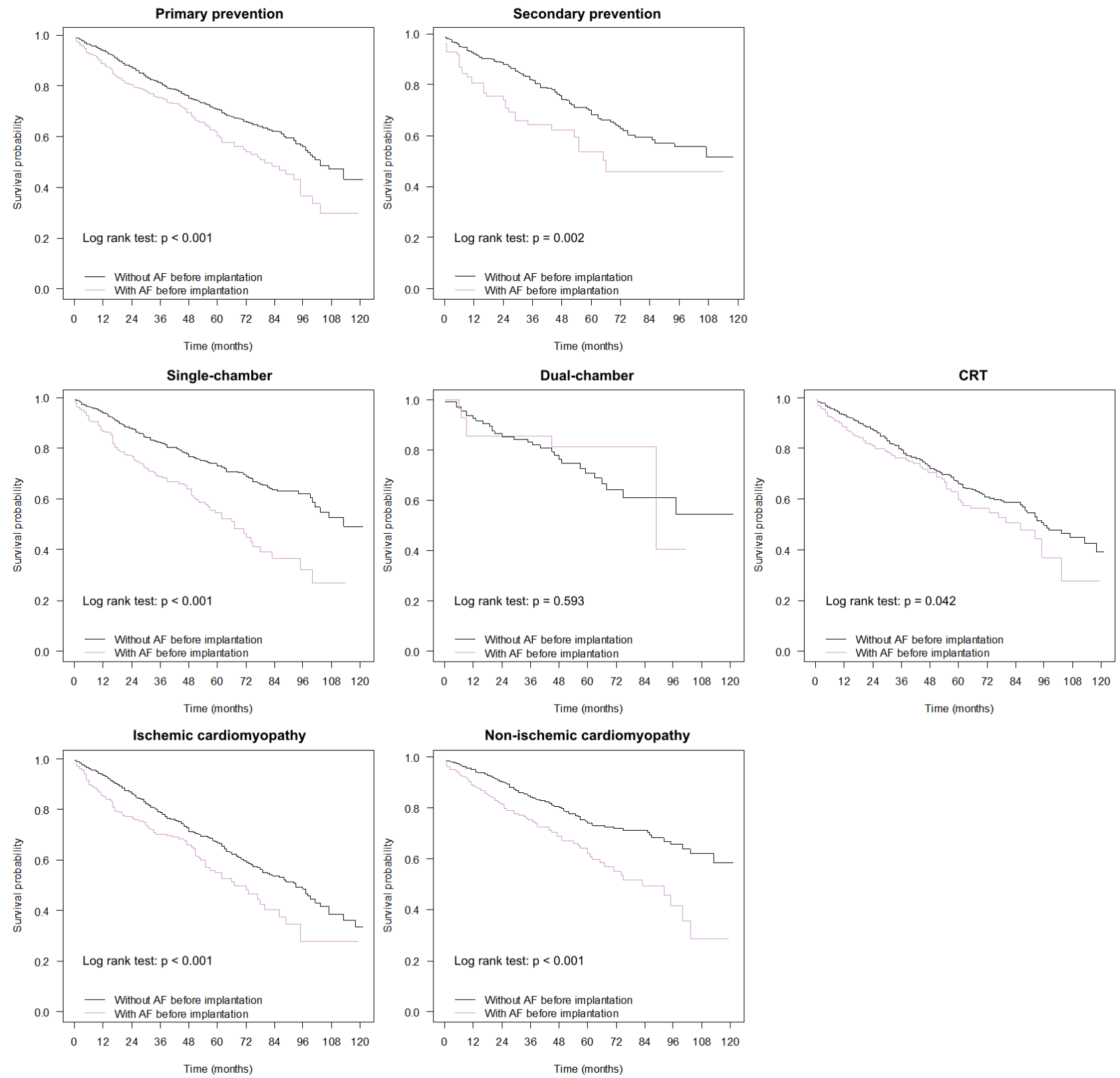

Fig. 6. Survival probability of all patients with or without atrial fibrillation prior to implantation according to the type of implantation, type of device, and type of cardiomyopathy.

\section{DISCUSSION}

Since the early 2000s, there has been an apparent gradual decrease in the mortality of HF patients in both observational and randomized studies ${ }^{4,12}$. This can be attributed to improvements in HF pharmacotherapy, a higher prevalence of CRT, and an optimized ICD programming ${ }^{13}$. Simultaneously, the rates of SCD have decreased, as have the numbers of appropriate life-saving ICD therapies. The average annual shock rate in the MADIT-II trial was $17 \%$, whereas the percentages of patients who had a life-saving shock were $3 \%$ and $4 \%$ in the Israeli ICD registry during a 30-month follow-up and in the MADIT-RIT during an average follow-up of 1.6 years, respectively ${ }^{6,14}$. An estimation based on the results of the Israeli ICD registry indicates that $95 \%$ of ICD re- cipients in the primary prevention indication category do not receive a life-saving ICD therapy ${ }^{6}$. ICDs cannot be implanted in all patients. This strategy is not viable due to limited healthcare resources, and implantation of ICD and CRT devices is not without risk as it is still associated with significant morbidity, increased hospitalizations, and reduced survival ${ }^{15}$. ICD implantation may have a significant impact on mortality only in patients with a low risk of non-arrhythmic mortality and a high risk of appropriate ICD intervention. Our analysis of a 10-year follow-up (a mean follow-up of $38.4 \pm 29.1$ months) of 2,681 consecutive patients with an implanted ICD in a contemporary real-world setting focused on finding subgroups of patients with significant differences in mortality, which could enable us to identify patients with a better outcome after ICD implantation. 

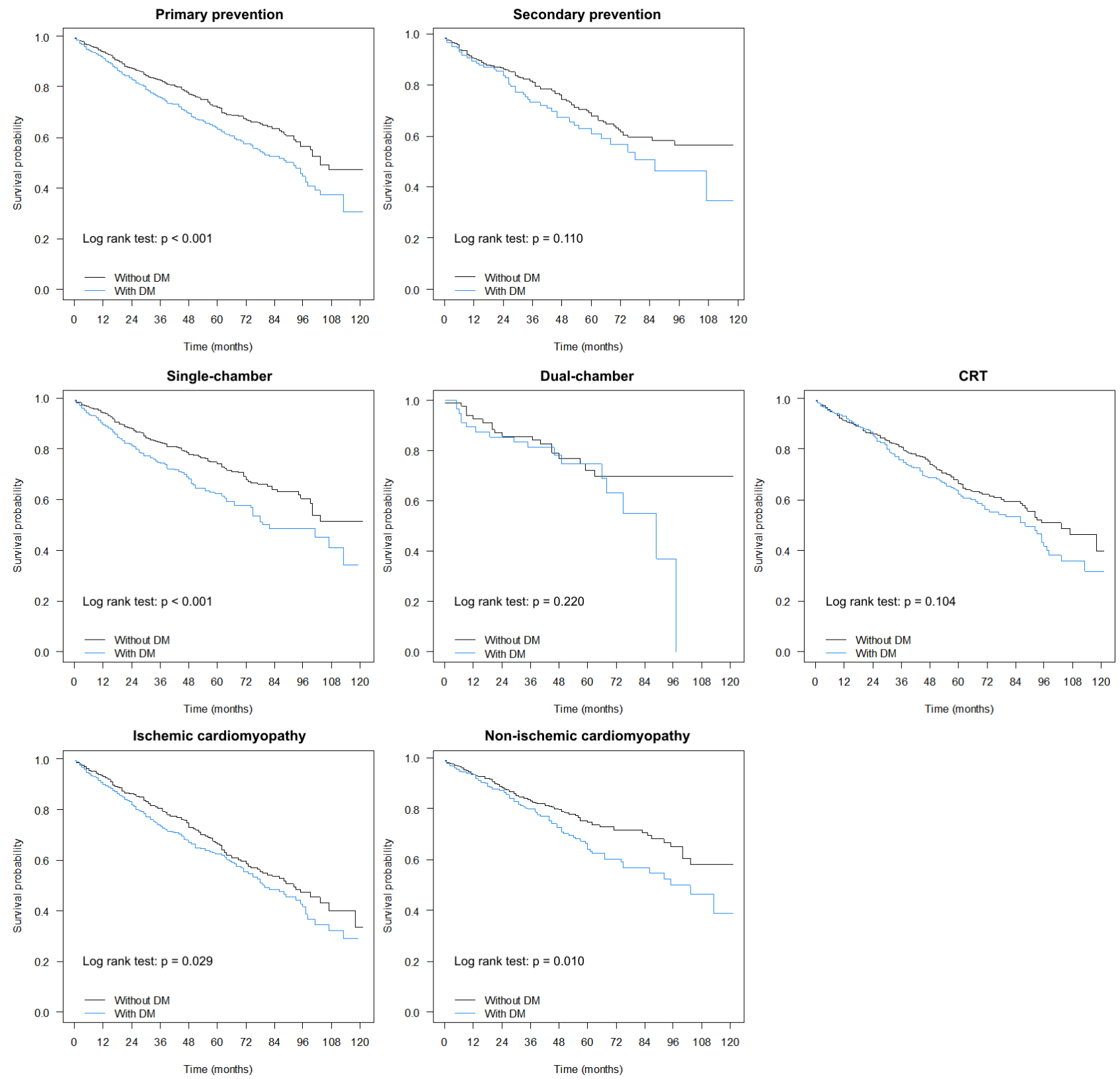

Fig. 7. Survival probability of all patients with or without diabetes mellitus prior to implantation according to the type of implantation, type of device, and type of cardiomyopathy.

In our patient group, the one-year mortality in all patients was $7.8 \%$, CV mortality $5.7 \%$; the three-year mortality in all patients $20.6 \%$, and CV mortality $14.8 \%$. The mortality in our patient group was higher when compared with the Israeli ICD registry which reported a mortality of $14 \%$ at 30 months of follow-up ${ }^{6}$. Moreover, data from the EU-CERT-ICD Multicentre Cohort Study showed a slightly lower mortality (5.6\% annual mortality in the ICD group) $\left(\right.$ ref. $\left.{ }^{10}\right)$. The somewhat higher mortality in our patient group could be explained by a high proportion of patients with severe comorbidities. Diabetes mellitus was present in almost $40 \%$ of patients, chronic renal insufficiency in $10 \%$, and $\mathrm{AF}$ in more than $22 \%$ of patients. The analysis of data from our registry focused on several parameters that were found most usable by previous studies. Barra et al. found that patients with ICM (ischemic cardiomyopathy) were more prone to die from arrhythmia than those with NICM (non-ischemic cardiomyopathy) $\left(\right.$ ref. $\left.{ }^{16}\right)$. Similar rates of appropriate ICD therapy in primary prevention ICD indication were documented in ICM and NICM by Amara et al. ${ }^{17}$. We documented a statistically significant difference in mortality when the subgroups were compared according to the type of cardiomyopathy. Patients with ICM had higher all-cause, CV, and non-CV mortality rates in comparison with NICM patients. In our study, $39.9 \%$ of all ICDs were CRT-Ds. This is a far higher number in comparison with studies from the early 2000s, and this proportion of CRT is comparable with that in the Israeli ICD registry where $45 \%$ of ICDs were CRT-D ${ }^{6}$. No significant difference was found between patients implanted for primary and secondary prevention indication and between the types of devices (1-D, 2-D ICD, and CRT-D). This is in accordance with the Danish ICD Register which demonstrated no differ- 
ence in the risk of all-cause mortality associated with the device type ${ }^{18}$.

A lower survival advantage in ICD patients was demonstrated in diabetics and patients older than 75 years in the EU-CERT-ICD controlled multicentre cohort study ${ }^{10}$. This finding is consistent with our data. In our study, there was a significantly higher mortality in all patients older than 75 years, irrespective of the device type or type of cardiomyopathy. When comparing diabetics with nondiabetics, there was no difference in mortality in patients with a dual-chamber ICD and CRT-D. In single-chamber ICDs, the difference in mortality was significant. Also, when patients were compared according to the type of cardiomyopathy, diabetes was associated with a significantly higher mortality risk in ICM as well as in NICM. Atrial fibrillation was found to be associated with an increased risk for mortality and HF progression in patients with asymptomatic and symptomatic left ventricular systolic dysfunction ${ }^{19}$. In our patient group, AF was associated with an increased mortality risk in all subgroups of patients except those with a dual-chamber ICD. This might be explained by a more frequent paroxysmal AF diagnosis in dual-chamber ICDs. Patients with more comorbidities and persistent or permanent AF are generally more often implanted a 1-D ICD or CRT-D with a subsequent AV node ablation. Women are generally less often present in clinical trials evaluating the benefit of ICD in HF patients ${ }^{20}$. In our registry, women were a minority as well (22.8\%). Women in general had a lower mortality than men. This mortality difference was driven by a significantly better survival of women than men with non-ischemic cardiomyopathy and with CRT. Our data confirm the significant differences in the mortality of individual subgroups of patients and further support the need for a new approach to risk stratification for SCD. A personalized assessment of the individual risk is the goal of the upcoming PROFID project $^{11}$.

Several study limitations need to be recognized. The main limitation is the observational nature of the study. There is no control group to be compared with the ICD group. Data on appropriate and inappropriate shocks were not included in the registry and are thus not available for analysis. Some information bias cannot be ruled out since the registry data were not checked externally.

\section{CONCLUSION}

In an analysis of a long-term follow-up of 2,681 ICD patients, we found no mortality difference between patients with ischemic or non-ischemic cardiomyopathy and in the device type. A higher mortality risk was found in men, patients older than 75 years, diabetics, and those with atrial fibrillation.

Author contributions: MT, TS: literature search, manuscript writing, data analysis, final approval; MF, VD, IS: follow-up of the patients; JJ, KB, MB, MV, JD: data analysis; JK: data analysis, final approval.
Conflict of interest statement: The authors state that there are no conflicts of interest regarding the publication of this article.

\section{REFERENCES}

1. Moss AJ, Zareba W, Hall WJ, Klein H, Wilber DJ, Cannom DS, Daubert JP, Higgins SL, Brown MW, Andrews ML; Multicenter Automatic Defibrillator Implantation Trial II Investigators. Prophylactic implantation of a defibrillator in patients with myocardial infarction and reduced ejection fraction. N Engl J Med 2002;346(12):877-83. doi: 10.1056/NEJMoa013474

2. Kadish A, Dyer A, Daubert JP, Quigg R, Estes NA, Anderson KP, Calkins H, Hoch D, Goldberger J, Shalaby A, Sanders WE, Schaechter A, Levine JH; Defibrillators in Non-Ischemic Cardiomyopathy Treatment Evaluation (DEFINITE) Investigators. Prophylactic defibrillator implantation in patients with nonischemic dilated cardiomyopathy. N Engl J Med 2004;350(21):2151-8. doi: 10.1056/NEJMoa033088

3. Bardy GH, Lee KL, Mark DB, Poole JE, Packer DL, Boineau R, Domanski M, Troutman C, Anderson J, Johnson G, McNulty SE, Clapp-Channing N, Davidson-Ray LD, Fraulo ES, Fishbein DP, Luceri RM, Ip JH; Sudden Cardiac Death in Heart Failure Trial (SCD-HeFT) Investigators. Amiodarone or an implantable cardioverter-defibrillator for congestive heart failure. N Engl J Med 2005;352(3):225-37. doi: 10.1056/ NEJMoa043399

4. Barra S, Providência R, Narayanan K, Boveda S, Duehmke R, Garcia R, Leyva F, Roger V, Jouven X, Agarwal S, Levy WC, Marijon E. Time trends in sudden cardiac death risk in heart failure patients with cardiac resynchronization therapy: a systematic review. Eur Heart J 2020;41(21):1976-86. doi: 10.1093/eurheartj/ehz773

5. Shen L, Jhund PS, Petrie MC, Claggett BL, Barlera S, Cleland JGF, Dargie HJ, Granger CB, Kjekshus J, Køber L, Latini R, Maggioni AP, Packer M, Pitt B, Solomon SD, Swedberg K, Tavazzi L, Wikstrand J, Zannad F, Zile MR, McMurray JJV. Declining Risk of Sudden Death in Heart Failure. N Engl J Med 2017;377(1):41-51. doi: 10.1056/ NEJMoa1609758

6. Sabbag A, Suleiman M, Laish-Farkash A, Samania N, Kazatsker M, Goldenberg I, Glikson M, Beinart R; Israeli Working Group of Pacing and Electrophysiology. Contemporary rates of appropriate shock therapy in patients who receive implantable device therapy in a real-world setting: From the Israeli ICD Registry. Heart Rhythm 2015;12(12):2426-33. doi: 10.1016/j.hrthm.2015.08.020

7. Narayanan K, Reinier K, Uy-Evanado A, Teodorescu C, Chugh $\mathrm{H}_{\text {, }}$ Marijon E, Gunson K, Jui J, Chugh SS. Frequency and determinants of implantable cardioverter defibrillator deployment among primary prevention candidates with subsequent sudden cardiac arrest in the community. Circulation;128(16):1733-8. doi: 10.1161/ CIRCULATIONAHA

8. Olsen T, Jørgensen OD, Nielsen JC, Thøgersen AM, Philbert BT, Johansen JB. Incidence of device-related infection in 97750 patients: clinical data from the complete Danish device-cohort (19822018). Eur Heart J 2019;40(23):1862-69. doi: 10.1093/eurheartj/ ehz316

9. Martens P, Nuyens D, Rivero-Ayerza M, Van Herendael H, Vercammen J, Ceyssens W, Luwel E, Dupont M, Mullens W. Sacubitril/valsartan reduces ventricular arrhythmias in parallel with left ventricular reverse remodeling in heart failure with reduced ejection fraction. Clin Res Cardiol 2019;108(10):1074-82. doi: 10.1007/s00392-019-01440-y

10. Zabel M, Willems R, Lubinski A, Bauer A, Brugada J, Conen D, Flevari P, Hasenfulb G, Svetlosak M, Huikuri HV, Malik M, Palovic N, Schmidt G, Sritharan R, SchologI S, Szavit-Nossan J, Traykov V, Tuinenburg AE, Willich SN, Harden M, Friede T, Hastrup J, Svendsen JH, Sticherling C, Merkely B; and the EU-CERTICD Study Investigators. Clinical effectiveness of primary prevention implantable cardioverter-defibrillators: results of the EU-CERT-ICD controlled multicentre cohort study. Eur Heart J 2020:41:3437-47. doi:10.1093/eurheartj/ehaa226

11. Dagres N, Peek N, Leclercq C, Hindricks G. The PROFID project. Eur Heart J 2020;41(39):3781-82. doi: 10.1093/eurheartj/ehaa645

12. Packer $M$. What causes sudden death in patients with chronic heart failure and a reduced ejection fraction? Eur Heart J 2020;41:1757-63.

13. Goldenberg I, Huang DT, Nielsen JC. The role of implantable cardio- 
verter-defibrillators and sudden cardiac death prevention: indications, device selection, and outcome. Eur Heart J 2020;41:2003-11.

14. Moss AJ, Schuger C, Beck CA, Brown MW, Cannom DS, Daubert JP Estes NA 3rd, Greenberg H, Hall WJ, Huang DT, Kautzner J, Klein H, McNitt S, Olshansky B, Shoda M, Wilber D, Zareba W; MADIT-RIT Trial Investigators. Reduction in inappropriate therapy and mortality through ICD programming. N Engl J Med 2012;367(24):2275-83. doi: 10.1056/NEJMoa1211107

15. Blomström-Lundqvist C, Traykov V, Erba PA, Burri H, Nielsen JC, Bongiorni MG, Poole J, Boriani G, Costa R, Deharo JC, Epstein LM, Sa'ghy L, Snygg-Martin U, Starck C, Tascini C, Strathmore N. European Heart Rhythm Association (EHRA) international consensus document on how to prevent, diagnose, and treat cardiac implantable electronic device infections-endorsed by the Heart Rhythm Society (HRS), the Asia Pacific Heart Rhythm Society (APHRS), the Latin American Heart Rhythm Society (LAHRS), International Society for Cardiovascular Infectious Diseases (ISCVID), and the European Society of Clinical Microbiology and Infectious Diseases (ESCMID) in collaboration with the European Association for Cardio-Thoracic Surgery (EACTS). Eur Heart J 2020;41:2012-32.

16. Barra S, Boveda S, Providência R, Sadoul N, Duehmke R, Reitan C, Borgquist R, Narayanan K, Hidden-Lucet F, Klug D, Defaye $P$ Gras D, Anselme F, Leclercq C, Hermida JS, Deharo JC, Looi KL, Chow AW, Virdee M, Fynn S, Le Heuzey JY, Marijon E, Agarwal S; French-UK-Sweden CRT Network. Adding Defibrillation Therapy to
Cardiac Resynchronization on the Basis of the Myocardial Substrate. J Am Coll Cardiol 2017;69(13):1669-78. doi: 10.1016/j.jacc.2017.01.042 17. Amara N, Boveda S, Defaye P, Klug D, Treguer F, Amet D, Perier MC Gras D, Algalarrondo V, Bouzeman A, Piot O, Deharo JC, Fauchier L, Babuty D, Bordachar P, Sadoul N, Marijon E, Leclercq C; DAI-PP Investigators. Implantable cardioverter-defibrillator therapy among patients with non-ischaemic vs. ischaemic cardiomyopathy for primary prevention of sudden cardiac death. Europace 2018;20(1):6572. doi: 10.1093/europace/euw379

18. Weeke P, Johansen JB, Jørgensen OD, Nielsen JC, Møller M, Videbæk R, Højgaard MV, Riahi S, Jacobsen PK. Mortality and appropriate and inappropriate therapy in patients with ischaemic heart disease and implanted cardioverter-defibrillators for primary prevention: data from the Danish ICD Register. Europace 2013;15(8):1150-7. doi: 10.1093/europace/eut017

19. Dries DL, Exner DV, Gersh BJ, Domanski MJ, Waclawiw MA, Stevenson LW. Atrial fibrillation is associated with an increased risk for mortality and heart failure progression in patients with asymptomatic and symptomatic left ventricular systolic dysfunction: a retrospective analysis of the SOLVD trials. Studies of Left Ventricular Dysfunction. J Am Coll Cardiol 1998;32(3):695-703. doi: 10.1016/s07351097(98)00297-6

20. Barra S, Narayanan K, Garcia R, Marijon E. Time to revisit implantable cardioverter-defibrillator implantation criteria in women. Eur Heart J 2020:ehaa970. doi: 10.1093/eurheartj/ehaa970 